\title{
New insights toward the acute non-thyroidal illness syndrome
}

\section{Simone Magagnin Wajner and Ana Luiza Maia*}

Thyroid Section, Endocrine Division, Hospital de Clínicas de Porto Alegre, Universidade Federal do Rio Grande do Sul, Porto Alegre, Brasil

Edited by:

Luca Persani, University of Milan, Italy

Reviewed by:

Luca Persani, University of Milan, Italy Alessandro Antonelli, University of

Pisa, Italy

\section{${ }^{*}$ Correspondence}

Ana Luiza Maia, Serviço de

Endocrinologia, Hospital de Clínicas

de Porto Alegre, Rua Ramiro

Barcelos, 2350, CEP 90035-003

Porto Alegre, Brasil.

e-mail:almaia@ufrgs.br
The non-thyroidal illness syndrome (NTIS) refers to changes in serum thyroid hormone levels observed in critically ill patients in the absence of hypothalamic-pituitary-thyroid primary dysfunction. Affected individuals have low T3, elevated rT3, and inappropriately normalTSH levels. The pathophysiological mechanisms are poorly understood but the acute and chronic changes in pituitary-thyroid function are probably the consequence of the action of multiple factors. The early phase seems to reflect changes occurring primarily in the peripheral thyroid hormone metabolism, best seen in humans since $80-90 \%$ of the circulating T3 are derived from the pro-hormone T4. The conversion of T4 to T3 is catalyzed by type 1 (D1) and type 2 (D2) deiodinases via outer-ring deiodination. In contrast, type 3 deiodinase (D3) catalyzes the inactivation of both T4 and T3. Over the last decades, several studies have attempted to elucidate the mechanisms underlying the changes on circulating thyroid hormones in NTIS. Increased inflammatory cytokines, which occurs in response to virtually any illness, has long been speculated to play a role in derangements of deiodinase expression. On the other hand, oxidative stress due to augmented reactive oxygen species (ROS) generation is characteristic of many diseases that are associated with NTIS. Changes in the intracellular redox state may disrupt deiodinase function by independent mechanisms, which might include depletion of the as yet unidentified endogenous thiol cofactor. Here we aim to present an updated picture of the advances in understanding the mechanisms that result in the fall of thyroid hormone levels in the acute phase of NTIS.

Keywords: non-thyroidal illness syndrome, oxidative stress, deiodinases, thyroid hormone
The non-thyroidal illness syndrome (NTIS), also known as low T3 syndrome or euthyroid sick syndrome, reflects alterations in thyroid hormone levels that occur in almost every form of acute or chronic illness (Larsen et al., 2008). The acute phase of critical illness, observed in a variety of clinical situations, is marked by low triiodothyronine (T3) and free T3 and high reverse T3 (rT3) levels. As the disease progresses, additional decreases in $\mathrm{T} 3$ and further reductions in the T3/rT3 ratio are observed, whereas thyrotropin (TSH) levels typically remain within the normal range or slightly increased (Kaptein et al., 1982; Mebis and Van den Berghe, 2011). The changes in serum thyroxine (T4) levels are more complex. At early stages, serum T4 tends toward normal levels but its fall is observed in severe or end-stage cases (Docter et al., 1993). About 50\% NTIS patients will also present decreased TSH levels, indicating concomitant changes in the hypothalamic/pituitary regulation (Fliers et al., 1997; Plikat et al., 2007). Whether these changes are due to adaptive physiological mechanisms to reduce the metabolic rate during stressful circumstances or a consequence of the underlying process is still a matter of debate.

The changes in thyroid hormone levels are associated with duration and severity of the disease. An entire set of data obtained from critically ill patients demonstrated that the degree of reduction in thyroid hormone levels correlates with patient mortality and that serum rT3, T3/rT3 ratio, and free T4 levels are independent prognostic factors for survival (Iervasi et al.,
2003; Peeters et al., 2005; Plikat et al., 2007). Low T3 levels are also an independent predictor of short- and long-term survival in patients with myocardial infarction, heart failure, or acute stroke outside the ICU setting (Iervasi et al., 2003; Iglesias et al., 2009).

The physiopathological mechanisms responsible for NTIS are complex and poorly understood, but acute and chronic changes in pituitary-thyroid function are probably the consequence of multiple factors. The endocrine and metabolic profiles differ from the acute stages and the prolonged critical illness, which may relate to the metabolic and immunological alterations accompanying the medical condition. The early phase of illness seems to reflect changes occurring primarily in the peripheral metabolism of thyroid hormones, best seen in humans since $80-90 \%$ of the circulating T3 are derived from T4, as opposed to rodents in which $50 \%$ or more of the $\mathrm{T} 3$ are released directly from the thyroid.

Neuroendocrine abnormalities seem to predominate in prolonged disease with reduced TSH levels being the most frequent abnormality (Plikat et al., 2007). Even though some patients present TSH levels within the reference ranges, the physiologic nocturnal surge of TSH does not occur, implying the involvement of hypothalamus. Loss of pulsatile fraction, decreased pulse amplitude, and absence of response to thyrotropin-releasing hormone (TRH) has also been reported (Sumita et al., 1994). A normal or even decreased TSH in the face of low circulating 
T3 levels indicates a major change in hypothalamic-pituitarythyroid (HPT) axis setpoint in the HPT axis. The mechanisms responsible for downregulation of the central HPT axis are still uncertain and most likely multifactorial (Fliers et al., 2006). These abnormalities tend to resolve and increases in TSH levels have been proposed as marker of recovery from severe illness (Van der Berghe, 2002). Impaired pulsatile secretion of growth hormone $(\mathrm{GH})$, prolactin (PRL), and luteinizing hormone (LH) have also been described. Moreover, the pituitary-adrenal axis shows a distinct response to acute and protracted critical illness (Van der Berghe, 2002).

Abnormalities of the thyroid hormone receptor expression (Rodriguez-Perez et al., 2008; Lado-Abeal et al., 2010) as well as of thyroid hormone transporters (Mebis et al., 2009) have been reported in acute and chronic NTIS. Thyroxine-binding globulin (TBG) may be low in the acute phase of illness, contributing to the low total T4, whereas it remains within the normal range in the chronic disease (Afandi et al., 2000).

This review will focus on the novel aspects of the pathophysiology of the acute phase of NTIS, particularly on the abnormalities of peripheral thyroid hormone metabolism.

\section{THYROID HORMONE METABOLISM - THE IODOTHYRONINE DEIODINASES}

The iodothyronine selenodeiodinases are a group of oxidoreductases that catalyze thyroid hormone activation and/or inactivation, constituting a potent mechanism that tightly regulates plasma and intracellular levels of thyroid hormone. The activation of the prohormone T4 into the biologically active hormone T3 is catalyzed by type 1 (D1) and type 2 (D2) deiodinases via outer-ring deiodination (Maia et al., 2005). In contrast, type 3 deiodinase (D3) catalyzes the inactivation of both T4 and T3. D1 and D2 differ by their kinetic properties, substrate specificity, and susceptibility to inhibitory drugs, as well as by their responses to changes in the thyroid hormone status. While D2 is an exclusive outer-ring deiodinase, D1 promotes inner ring as well as outer-ring deiodination. The higher levels of D1 activity in humans are found in thyroid, liver, and kidney, while D2 is more widely expressed, being found in the pituitary, brain, thyroid, skin, skeletal, and heart muscle (Maia et al., 2011; Williams and Bassett, 2011). The selenoenzyme D3 catalyzes essentially the inner ring of T4, promoting the conversion of T4 to rT3 and the conversion of T3 to 3,3'-T2, both biologically inactive. D3 contributes to thyroid hormone homeostasis protecting tissue from excess of thyroid hormones.

All three deiodinases are members of the thioredoxin family and require a thiol cofactor for the enzymatic reaction. This as yet unidentified cofactor represents the main gap in the current knowledge. Early studies of D1-catalyzed reaction suggest glutathione (GSH) and thioredoxin (TRX) as possible candidates, since both were shown to be effective in supporting the enzymatic catalysis in in vitro experiments (Goswami and Rosenberg, 1987; St. Germain, 1988; Goemann et al., 2010). Little is known about the possible cofactor for D2 and D3, although GSH has been suggested as a potential candidate (St. Germain, 1988). The proposed mechanism for the enzymatic reaction of D1 involves the interaction of the sulfhydryl group of the enzyme cysteine (Cys) residue with the second substrate. The thiol-containing cofactor would act as a reducing agent regenerating the active enzyme (Goswami and Rosenberg, 1984). For the D2 or D3-catalyzed reactions, the thiol-containing cofactor must interact with the enzyme simultaneously before reaction takes place (Kuiper et al., 2002, 2003). Interestingly, two thiol groups are required for the D2-catalyzed reaction, suggesting that this enzyme would be more susceptible to cofactor depletion (Kuiper et al., 2002).

Considering that about $80 \%$ of plasma T3 in humans is derived from peripheral conversion of $\mathrm{T} 4$, the prompt reduction of $\mathrm{T} 3 \mathrm{lev}$ els as observed in NTIS must be, at least in part, due to decreased peripheral conversion by D1 and/or D2. Indeed, serum T3 levels decrease as early as $2 \mathrm{~h}$ of the onset of acute stress (Van der Berghe, 2002), which can be explained by a decrease in D1 and/or D2-derived T3 production. Low D1 activity also explains the mild elevation of serum rT3 levels observed in the early phase of disease. These assumptions are supported by studies that measured D1 activity in hepatic biopsies of ICU patients showing decreased activity of this enzyme and a correlation between decreased D1 activity and increased serum rT3 levels (Peeters et al., 2003, 2005; Rodriguez-Perez et al., 2008). The role of D2 is still poorly defined, since the analysis of D2 activity in NTIS in humans has provided conflicting results. While some authors did not identify D2 activity in the muscular tissue of critically ill patients, others demonstrated normal (Peeters et al., 2003, 2005; Rodriguez-Perez et al., 2008), or even elevated D2 activity (Mebis et al., 2007). Intriguingly, D2 activity, but not D1, was found to be correlated with the low levels of serum T3 in a cohort of critically ill patients (Peeters et al., 2003, 2005).

Increased levels of D3 activity have been identified in liver and skeletal muscle of sick patients (Peeters et al., 2003, 2005; Debaveye et al., 2005; Rodriguez-Perez et al., 2008). Increased D3 activity will further decrease plasma T3 and increase the production of rT3 from T4. Indeed, a positive correlation has been demonstrated between the levels of rT3 and the increased activity of D3 in these tissues. Figure 1 summarizes the changes in deiodinase expression and consequent changes on serum thyroid hormone levels in NTIS.

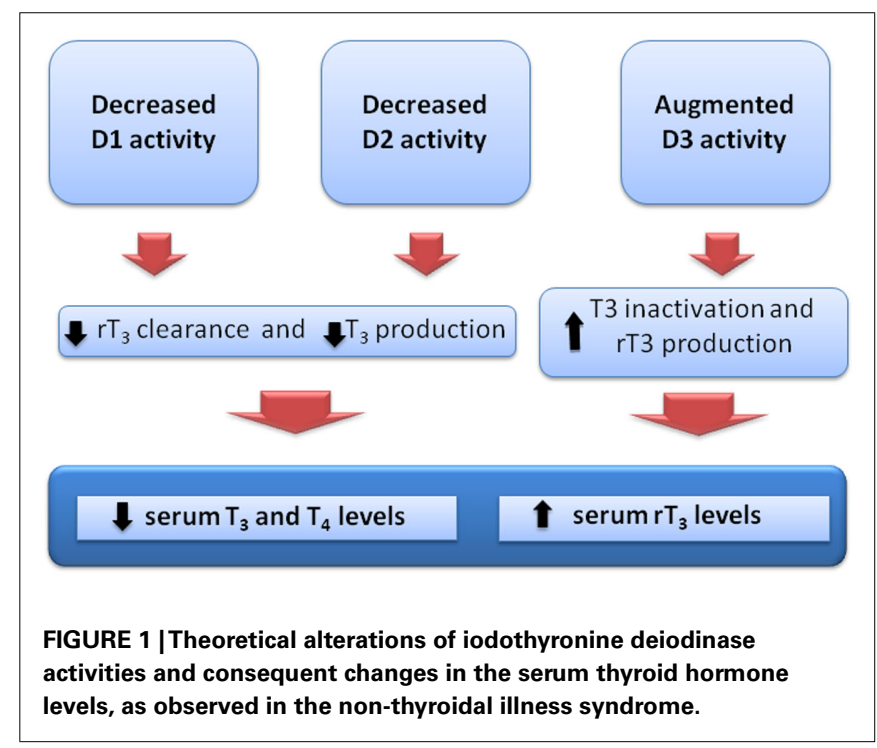




\section{THE ROLE OF INFLAMMATORY CYTOKINES AND OXIDATIVE} STRESS IN NTIS

Given that NTIS occurs in response to virtually any illness or surgical stress, the primary signal is expected to be a factor(s) common to all these conditions. In this context, particular attention has been focused on the cytokines, which are elevated as a generalized response to illness. Cytokines are autocrine and paracrine signaling peptide messengers working in a complex network that act in the immune system and coordinate the inflammatory response. Although a large number of pro- and anti-inflammatory cytokines are of importance, available data suggest that the interleukin (IL)$\beta$, tumor necrosis factor- $\alpha$ (TNF- $\alpha$ ), and, particularly, IL- 6 play a role in the pathogenesis of NTIS. Stimulation of the IL- 6 signaling pathway occurs via the IL-6R/gp130 receptor and initiates the IL-6 signal transduction. Ligand binding to the IL-6-receptor followed by the assembly of the receptor complex leads to initiation of the Janus Kinase (JAK)/signal transducer and activator of transcription (STAT) pathway as well as to the activation of the mitogen activated protein kinase (MAPK) and extracellular related kinase (ERK) cascades (Zauberman et al., 1999; Sano et al., 2001).

Interestingly, acute and chronically ill patients have an inverse correlation between the serum IL- 6 and T3 concentrations (Boelen et al., 1993, 1995; Bartalena et al., 1994; Davies et al., 1996; Friberg et al., 2002). Moreover, a single intravenous injection of IL-6, given to healthy humans, causes a transient decrease in serum T3 and an increase in rT3, changes that are characteristic of the NTIS (Torpy et al., 1998). Based on these observations, a potential effect of cytokines over deiodinase function has long been speculated (Fujii et al., 1989; Davies et al., 1997; Jakobs et al., 2002). Nevertheless, the conclusions are uncertain. Cytokines inhibit the expression and function of D1 in human hepatocellular carcinoma cells (HepG2; Yu and Koenig, 2000) whereas studies of rat hepatocyte cells have demonstrated that IL-1 and IL-6 impair T3mediated induction of D1 mRNA by a mechanism that involves an interaction with the thyroid hormone receptor (Yu and Koenig, 2000; Jakobs et al., 2002). Studies performed in mice hepatic cells have shown that $\mathrm{TNF} \alpha$, IL-1 $\beta$, or IL- 6 induces increases in D1 activity (Fujii et al., 1989; Davies et al., 1997). Additionally, studies focused on cytokine effects over D2 activity are scarce and controversial. While an increase in D2 activity was observed in GH3 pituitary cells after incubation with TNFa or IL-6 (Baur et al., 2000), human skeletal muscle cells showed a decreased D2 activity in the presence of high TNF $\alpha$ concentrations (Hosoi et al., 1999).

Oxidative stress, due to augmented ROS or nitrogen species (RNS) generation is also a characteristic of many diseases that are associated with NTIS (Abiles et al., 2006). Under physiological conditions, the cytosol is a strongly reducing environment. This is accomplished by the redox-buffering capacity of intracellular thiols, primarily the non-enzymatic antioxidants GSH and TRX. GSH is a ubiquitous tripeptide ( $\mathrm{L}-\gamma$-glutamil-L-cysteinylglycine) synthesized intracellularly and usually the most prevalent intracellular thiol (Meister and Anderson, 1983). TRX, in turn, is a small multifunctional protein that has a redox-active disulfide/dithiol within the conserved active site residues and is capable of reducing ROS, as well as refolding oxidized proteins (Valko et al., 2007). Patients with NTIS usually have reduced plasma and intracellular levels of antioxidant scavenging molecules as well as decreased activity of the antioxidant enzymatic system involved in ROS detoxification (Hammarqvist et al., 1997; Schafer and Buettner, 2001; Abiles et al., 2006). Upon oxidation, the cysteine residues within proteins can be modified to different products, including reversible interor intra-molecular disulfide bonds (S-S) and glutathione-mixed disulfides (GSS). Of note, the thiol group of cysteine residues in proteins is usually the most easily oxidized site within proteins and the most easily reversed (Guezzi et al., 2005; Gallogly et al., 2009).

The increased production of pro-inflammatory cytokines such as IL-6, a typical feature in NTIS, has been implicated in oxidative stress generation. IL- 6 is known to elicit an oxidative burst with the increase in superoxide radical $\left(\mathrm{O}_{2}\right)$ production through the activation of the nicotine adenine dinucleotide phosphate $[\mathrm{NAD}(\mathrm{P}) \mathrm{H}]$ oxidase pathway (Valko et al., 2007). The augmented ROS in turn depletes intracellular GSH decreasing the GSH/GSSG ratio (Meier et al., 1989; Haddad and Harb, 2005; Valko et al., 2007). These changes in the intracellular redox state can disrupt deiodinase function by independent mechanisms. The increased ROS is likely to deplete thiol cofactor(s), thus impairing reactions which require a reductive intracellular environment, such as the deiodinases (Figure 2). Incorporation of selenocysteine can also be substantially reduced after treatment of cells with agents that cause oxidative stress, due to nuclear sequestration of the SECIS binding protein 2 (SBP2), which, under such conditions, might represent a mechanism to regulate the expression of selenoproteins (Papp et al., 2006; Lu and Holmgren, 2009).

Recently, the effects of cytokines, at pathophysiological concentrations as observed in NTIS, were investigated in a human cell culture system that mimics the physiological actions of the endogenous deiodinase cofactor(s) and FT4 levels (Wajner et al., 2011). It was observed that IL-6 inhibits T3 production by recombinant or endogenous D1 and D2 while it elicits an increase in all three deiodinase mRNAs, suggesting an impairment of the enzymatic reactions. Interestingly, the addition of $\mathrm{N}$-acetyl cysteine (NAC), an antioxidant that increases intracellular glutathione levels, prevented the inhibitory effect of IL-6 on D1- and D2-mediated T4 to T3 conversion, indicating that IL-6 inhibits the function of D1 and D2 by increasing cellular ROS thereby reducing glutathione (GSH), or a GSH-dependent, endogenous cofactor. In contrast, IL6 stimulates endogenous D3-mediated inactivation of T3, which is probably secondary to the plasma membrane location of D3 that allows this enzyme to have ready access to extracellular GSH (Figure 2). These findings provide a single mechanistic explanation for the associated changes in the deiodination pathway to explain the thyroid hormone changes as observed in the acute phase of NTIS. The IL- 6 induced decrease in D1 will both reduce plasma T3 production and rT3 clearance, while the decrease in D2 will complement this by impairing intracellular T4 to T3 conversion. Conversely, the increased D3 activity will further decrease plasma T3 and increase the production of rT3 from T4.

The effect of oxidative stress on deiodinase expression has been also demonstrated in astrocytes and in pulmonary arterial hypertension-induced heart failure in rats. In the first model, the addition of $\mathrm{H}_{2} \mathrm{O}_{2}$ increases thyroid hormone degradation through D3 activation while inhibiting the stimulated activation of T4 


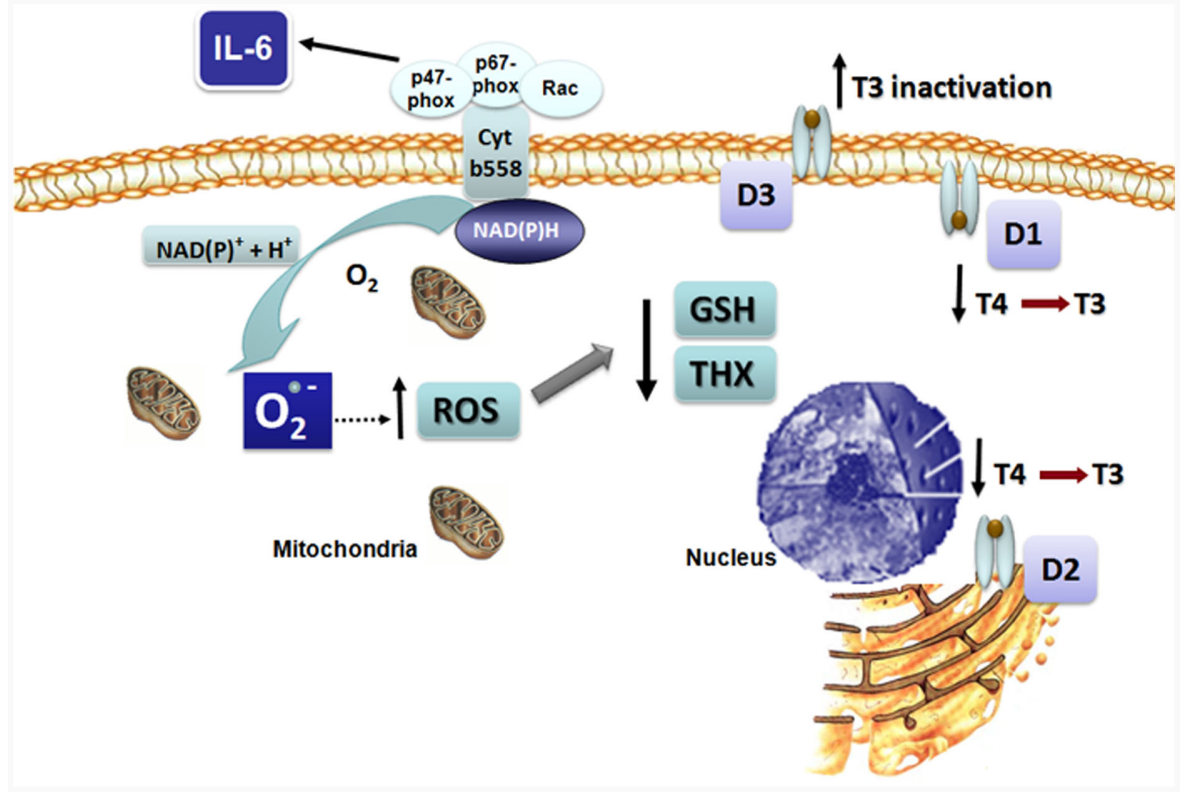

FIGURE 2 | Proposed mechanism for the effects of IL-6 on reactive oxygen species (ROS) formation and deiodinase function resulting in non-thyroidal illness syndrome (NTIS). IL-6 leads to intracellular superoxide formation and oxidative stress. Impaired function of D1 and D2 secondary to diminished intracellular thiol concentrations results in decreased T4 to T3 conversion, while increase D3 activity augments T3 inactivation. into T3, secondary to D2 inhibition. In heart failure, the induction in D3 expression is fully prevented by antioxidant treatment (Lamirand et al., 2008; Redout et al., 2010).

\section{SPARING ENERGY FOR METABOLIC REQUIREMENTS OR SELENIUM FOR GLUTATHIONE PEROXIDASE?}

Is the decrease of thyroid hormone levels in the NTIS beneficial or detrimental to patients? Although NTIS patients might be evaluated as euthyroid regarding serum TSH levels, many authors have advocated that they would benefit from thyroid hormone replacement (Utiger, 1995; Bennett-Guerrero et al., 1996; Dulawa et al., 2007; Pingitore et al., 2008). The proposed physiopathological grounds for this comes from the fact that intratissular hypothyroidism would lead to exacerbation of the pathology itself. However, this assertion is still a controversial matter.

The rationale for thyroid hormone replacement on NTIS is indeed multifaceted. Thyroid hormone increases the metabolic activity of almost all body tissues. Mitochondrial oxygen consumption has been shown to be increased in the hyperthyroid state, suggesting that excessive amounts of ROS might be generated in this situation (Venditti and Di Meo, 2006). Moreover, the administration of $\mathrm{T} 3$ to euthyroid rats stimulates the $\mathrm{NAD}(\mathrm{P}) \mathrm{H}$-supported generation of superoxide radical (Fernandez et al., 1985). Thus, lowering thyroid hormone could decrease the energy expenditure and contribute to calorie-sparing economy. In this context, the increment in cellular ROS levels could even be considered as a compensatory mechanism that protects the cells against further increase in free radicals by decreasing the metabolic state. The role of selenium in oxidative stress might also be of importance. Since GPx is a selenoenzyme, the physiological function of GPx protection against ROS could impact the available selenium to prevent oxidative stress, making this molecule insufficient to support the deiodinase production.

Accordingly, clinical studies have shown conflicting results. No benefit was observed for survival in patients with acute renal failure or renal transplantation, as well as intensive care patients randomly assigned to receive intravenous T4 or T3 vs. placebo (Brent and Hershman, 1986; Acker et al., 2000, 2002). Moreover, thyroid hormone was of no benefit in long-term outcomes of patients with severe congestive heart failure (Pingitore et al., 2008) or in patients who underwent myocardial revascularization (Bennett-Guerrero et al., 1996). Other studies even indicate that T3 replacement might have negative effects on protein and fat metabolism (Axelrod et al., 1983; Lim et al., 1985; Dulawa et al., 2007). Controversially, several others support a potential positive effect of thyroid hormone replacement on NTIS. Thyroid hormone administration has been shown to stabilize the function of the cardiovascular system of organ donors (Taniguchi et al., 1992). Similarly, T3 treatment has been shown to improve hemodynamic parameters in patients undergoing coronary artery bypass graft surgery (Bennett-Guerrero et al., 1996) or with severe congestive heart failure (Malik et al., 1999). In children, treatment with T3 after cardiopulmonary bypass operations improves myocardial function and reduces the need for postoperative intensive care (Bettendorf et al., 2000). A recent study addressed the effect of acute T3 infusion on cardiac function in patients with stable ischemic or non-ischemic LV dysfunction. It was shown that short-term synthetic 1-T3 replacement significantly improved the neuroendocrine profile and ventricular performance (Pingitore et al., 2008).

A recent systematic review on thyroid hormone therapy for postoperative non-thyroidal illnesses concludes that postoperative 
intravenous T3 therapy increases cardiac index but does not alter mortality. The effects on other hemodynamic parameters as well as the effects of oral T3 replacement were inconclusive. The authors bring to light the small number of usable unique studies, small group sizes, short-time of T3 therapy as well as the differences on dosages and routes of administration (Kaptein et al., 2010).

\section{CONCLUSION}

It has been known for decades that sick patients have low serum T3 and increased rT3, a clinical entity known as NTIS. Although several factors in sick patients are supposed to contribute to NTIS, the prompt reduction of T3 concomitant with increases in rT3 levels must be, at least in part, due to derangements in the peripheral

\section{REFERENCES}

Abiles, J., de la Cruz, A. P., Castano, J., Rodríguez-Elvira, M., Aguayo, E., Moreno-Torres, R., Llopis, J., Aranda, P., Argüelles, S., Ayala, A., de la Quintana, A. M., and Planells, E. M. (2006). Oxidative stress is increased in critically ill patients according to antioxidant vitamins intake, independent of severity: a cohort study. Crit. Care 10, R146.

Acker, C. G., Flick, R., Shapiro, R., Scantlebury, V. P., Jordan, M. L., Vivas, C., Greenberg, A., and Johnson, J. P. (2002). Thyroid hormone in the treatment of post-transplant acute tubular necrosis (ATN). Am. J. Transplant. 2, 57-61.

Acker, C. G., Singh, A. R., Flick, R. P., Bernardini, J., Greenberg, A., and Johnson, J. P. (2000). A trial of thyroxine in acute renal failure. Kidney Int. 57, 293-298.

Afandi, B., Vera, R., and Schussler, G. C. (2000). Concordant decreases of thyroxine and thyroxine binding protein concentrations during sepsis. Metabolism 49, 753-754.

Axelrod, L., Halter, J. B., Cooper, D. S., Aoki, T. T., Roussell, A. M., and Bagshaw, S. L. (1983). Hormone levels and fuel flow in patients with weight loss and lung cancer. Evidence for excessive metabolic expenditure and for an adaptive response mediated by a reduced level of 3,5,3'-triiodothyronine. Metabolism 32, 924-937.

Bartalena, L., Brogioni, S., Grasso, L., Velluzzi, F., and Martino, E. (1994). Relationship of the increased serum interleukin-6 concentration to changes of thyroid function in nonthyroidal illness. J. Endocrinol. Invest. 17, 269-274.

Baur, A., Bauer, K., Jarry, H., and Kohrle, J. (2000). Effects of proinflammatory cytokines on anterior pituitary $5^{\prime}$-deiodinase type I and type II. J. Endocrinol. 167, 505-515.
Bennett-Guerrero, E., Jimenez, J. L., White, W. D., D’Amico, E. B., Baldwin, B. I., and Schwinn, D. A. (1996). Cardiovascular effects of intravenous triiodothyronine in patients undergoing coronary artery bypass graft surgery. A randomized, doubleblind, placebo-controlled trial. Duke T3 study group. JAMA 275, 687-692. Bettendorf, M., Schmidt, K. G., GrulichHenn, J., Ulmer, H. E., and Heinrich, U. E. (2000). Tri-iodothyronine treatment in children after cardiac surgery: a double-blind, randomised, placebo-controlled study. Lancet 356, 529-534.

Boelen, A., Platvoet-Ter Schiphorst, M. C., and Wiersinga, W. M. (1993). Association between serum interleukin-6 and serum 3,5,3'triiodothyronine in nonthyroidal illness. J. Clin. Endocrinol. Metab. 77, 1695-1699.

Boelen, A., Platvoet-Ter Schiphorst, M. C., and Wiersinga, W. M. (1995). Soluble cytokine receptors and the low 3,5,3'-triiodothyronine syndrome in patients with nonthyroidal disease. J. Clin. Endocrinol. Metab. 80, 971-976.

Brent, G. A., and Hershman, J. M. (1986). Thyroxine therapy in patients with severe nonthyroidal illnesses and low serum thyroxine concentration. J. Clin. Endocrinol. Metab. 63, 1-8.

Davies, P. H., Black, E. G., Sheppard, M. C., and Franklyn, J. A. (1996). Relation between serum interleukin6 and thyroid hormone concentrations in 270 hospital in-patients with non-thyroidal illness. Clin. Endocrinol. (Oxf.) 44, 199-205.

Davies, P. H., Sheppard, M. C., and Franklyn, J. A. (1997). Inflammatory cytokines and type I $5^{\prime}$-deiodinase expression in F1 rat liver cells. Mol. Cell. Endocrinol. 129, 191-198.

Debaveye, Y., Ellger, B., Mebis, L., Van Herck, E., Coopmans, W., Darras,

thyroid hormone metabolism which is largely dependent on the proper functioning of the iodothyronine deiodinases. IL-6 levels is increased as a generalized response to disease, leading to increase in ROS production and consequent depletion of intracellular thiols, which might explain an impairment of deiodinase function. Taken together, these observations lead to a previously unrecognized combinatorial pathway in which the NTIS may be viewed largely as a general response of the sick body to oxidative stress, a step forward in unraveling the long-standing enigma of NTIS pathogenesis. The dilemma about treating or not NTIS patients remains unsettled, but progress in understanding the physiopathological mechanisms that result in the fall of thyroid hormone levels in critically ill patients is essential in the search for the adequate therapeutic approach.

V., and Van den Berghe, G. (2005). Tissue deiodinase activity during prolonged critical illness: effects of exogenous thyrotropin-releasing hormone and its combination with growth hormone-releasing peptide2. Endocrinology 146, 5604-5611.

Docter, R., Krenning, E. P., de Jong, M., and Hennemann, G. (1993) The sick euthyroid syndrome: changes in thyroid hormone serum parameters and hormone metabolism. Clin. Endocrinol. (Oxf.) 39, 499-518.

Dulawa, A., Buldak, L., Krysiak, R., and Okopień, B. (2007). Hormonal supplementation in endocrine dysfunction in critically ill patients. Pharmacol. Rep. 59, 139-149.

Fernandez, V., Barrientos, X., Kipreos, K., Valenzuela, A., and Videla, L. A. (1985). Superoxide radical generation and cytochrome P-450 content of rat liver microssomal fractions in an experimental hyperthyroid state: relation to lipid peroxidation. Endocrinology 117, 496-501.

Fliers, E., Guldenaar, S. E., Wiersinga, W. M., and Swaab, D. F. (1997). Decreased hypothalamic thyrotropin-releasing hormone gene expression in patients with nonthyroidal illness. J. Clin. Endocrinol. Metab. 82, 4032-4036.

Fliers, E., Alkemade, A., Wiersinga, W. M., and Swaab, D. F. (2006). Hypothalamic thyroid hormone feedback in health and disease. Prog. Brain Res. 153, 189-207.

Friberg, L., Werner, S., Eggertsen, G., and Ahnve, S. (2002). Rapid downregulation of thyroid hormones in acute myocardial infarction: is it cardioprotective in patients with angina? Arch. Intern. Med. 162, 1388-1394.

Fujii, T., Sato, K., Ozawa, M., Kasono, K., Imamura, H., Kanaji, Y., Tsushima, T., and Shizume, K. (1989). Effect of interleukin-1 (IL-1) on thyroid hormone metabolism in mice: stimulation by IL- 1 of iodothyronine $5^{\prime}$ deiodinating activity (type I) in the liver. Endocrinology 124, 167-174.

Gallogly, M. M., Starke, D. W., and Mieyal, J. J. (2009). Mechanistic and kinetic details of catalysis of thioldisulfide exchange by glutaredoxins and potential mechanisms of regulation. Antioxid. Redox Signal. 11, 1059-1081.

Goemann, I. M., Gereben, B., Harney, J. W., Zhu, B., Maia, A. L., and Larsen, P. R. (2010). Substitution of serine for proline in the active center of type 2 iodothyronine deiodinase substantially alters its in vitro biochemical properties with dithiothreitol but not its function in intact cells. Endocrinology 151, 821-829.

Goswami, A., and Rosenberg, I. N. (1984). Iodothyronine 5' -deiodinase in rat kidney microsomes. Kinetic behavior at low substrate concentrations. J. Clin. Invest. 74, 2097-2106.

Goswami, A., and Rosenberg, I. N. (1987). Thioredoxin stimulates enzymatic outer ring monodeiodination of reverse triiodothronine. Endocrinology 121, 1937-1945.

Guezzi, P., Bonetto, V., and Fratelli, M. (2005). Thiol-dissulfide balance: from the concept of oxidative stress to that of redox regulation. Antioxid. Redox Signal. 7, 964-972.

Haddad, J. J., and Harb, H. L. (2005). L-gamma-glutamyl-L-cysteinylglycine (glutathione; GSH) and GSH-related enzymes in the regulation of pro- and anti-inflammatory cytokines: a signaling transcriptional scenario for $\operatorname{redox}(\mathrm{y})$ immunologic sensor(s)? Mol. Immunol. 42, 987-1014.

Hammarqvist, F., Luo, J. L., Cotgreave, I. A., Andersson, K., and Wernerman, J. (1997). Skeletal muscle glutathione is depleted in critically ill patients. Crit. Care Med. 25, 78-84. 
Hosoi, Y., Murakami, M., Mizuma, H., Ogiwara, T., Imamura, M., and Mori, M. (1999). Expression and regulation of type II iodothyronine deiodinase in cultured human skeletal muscle cells. J. Clin. Endocrinol. Metab. 84, 3293-3300.

Iervasi, G., Pingitore, A., Landi, P., Raciti, M., Ripoli, A., Scarlattini, M., L'Abbate, A., and Donato, L. (2003). Low-T3 syndrome: a strong prognostic predictor of death in patients with heart disease. Circulation 107, 708-713.

Iglesias, P., Muñoz, A., Prado, F., Guerrero, M. T., Macías, M. C., Ridruejo, E., Tajada, P., and Díez, J. J. (2009). Alterations in thyroid function tests in aged hospitalized patients: prevalence, aetiology and clinical outcome. Clin. Endocrinol. (Oxf.) 70, 961-967.

Jakobs, T. C., Mentrup, B., Schmutzler, C., Dreher, I., and Kohrle, J. (2002). Proinflammatory cytokines inhibit the expression and function of human type I $5^{\prime}$-deiodinase in HepG2 hepatocarcinoma cells. Eur. J. Endocrinol. 146, 559-566.

Kaptein, E. M., Robinson, W. J., Grieb, D. A., and Nicoloff, J. T. (1982). Peripheral serum thyroxine, triiodothyronine and reverse triiodothyronine kinetics in the low thyroxine state of acute nonthyroidal illnesses. A noncompartmental analysis. J. Clin. Invest. 69, 526-535.

Kaptein, E. M., Sanchez, A., Beale, E., and Chan, L. S. (2010). Clinical review: thyroid hormone therapy for postoperative nonthyroidal illnesses: a systematic review and synthesis. J. Clin. Endocrinol. Metab. 95, 4526-4534.

Kuiper, G. G., Klootwijk, W., and Visser, T. J. (2002). Substitution of cysteine for a conserved alanine residue in the catalytic center of type II iodothyronine deiodinase alters interaction with reducing cofactor. Endocrinology 143, 1190-1198.

Kuiper, G. G., Klootwijk, W., and Visser, T. J. (2003). Substitution of cysteine for selenocysteine in the catalytic center of type III iodothyronine deiodinase reduces catalytic efficiency and alters substrate preference. Endocrinology 144, 2505-2513.

Lado-Abeal, J., Romero, A., CastroPiedras, I., Rodriguez-Perez, A., and Alvarez-Escudero, J. (2010). Thyroid hormone receptors are down-regulated in skeletal muscle of patients with non-thyroidal illness syndrome secondary to nonseptic shock. Eur. J. Endocrinol. 163, 765-773.
Lamirand, A., Pallud-Mothre, S., Ramauge, M., Pierre, M., and Courtin, F. (2008). Oxidative stress regulates type 3 deiodinase and type 2 deiodinase in cultured rat astrocytes. Endocrinology 149, 3713-3721.

Larsen, P. R., Davies, T. F., Schlumberger, M. J., Hay, I. A. (2008). "Thyroid Physiology and diagnostic evaluation of patients with thyroid disorders," in Williams Textbook of Endocrinology, eds H. M. Kronenberg, S. Melmed, K. S. Polonsky, and P. R. Larsen (Philadelphia, PA: Saunders Elsevier), 499-442.

Lim, V. S., Flanigan, M. J., Zavala, D. C., and Freeman, R. M. (1985). Protective adaptation of low serum triiodothyronine in patients with chronic renal failure. Kidney Int. 28, 541-549.

Lu, J., and Holmgren, A. (2009). Selenoproteins. J. Biol. Chem. 284, 723-727.

Maia, A. L., Goemann, I. M., Meyer, E. L., and Wajner, S. M. (2011). Deiodinases: the balance of thyroid hormone: type 1 iodothyronine deiodinase in human physiology and disease. J. Endocrinol. 209, 283-297.

Maia, A. L., Kim, B. W., Huang, S. A., Harney, J. W., and Larsen, P. R. (2005). Type 2 iodothyronine deiodinase is the major source of plasma T3 in euthyroid humans. J. Clin. Invest. 115, 2524-2533.

Malik, F. S., Mehra, M. R., Uber, P. A., Park, M. H., Scott, R. L., and Van Meter, C. H. (1999). Intravenous thyroid hormone supplementation in heart failure with cardiogenic shock. J. Card. Fail. 5, 31-37.

Mebis, L., Langouche, L., Visser, T. J., and Van den Berghe, G. (2007). The type II iodothyronine deiodinase is up-regulated in skeletal muscle during prolonged critical illness. J. Clin. Endocrinol. Metab. 92, 3330-3333.

Mebis, L., Palettam, D., Debaveye, Y., Ellger, B., Langouche, L., D'Hoore, A., Darras, V. M., Visser, T. J., and Van den Berghe, G. (2009). Expression of thyroid hormone transporters during critical illness. Eur. J. Endocrinol. 161, 243-250

Mebis, L., and Van den Berghe, G. (2011). Thyroid axis function and dysfunction in critical illness. Best Pract. Res. Clin. Endocrinol. Metab. 25, 745-757.

Meier, B., Radeke, H. H., Selle, S., Younes, M., Sies, H., Resch, K., and Habermehl, G. G. (1989). Human fibroblasts release reactive oxygen species in response to interleukin1 or tumour necrosis factor-alpha. Biochem. J. 263, 539-545.
Meister, A., and Anderson, M. E. (1983) Glutathione. Annu. Rev. Biochem. 52, 711-760.

Papp, L. V., Lu, J., Striebel, F., Kennedy, D., Holmgren, A., and Khanna, K. K. (2006). The redox state of SECIS binding protein 2 controls its localization and selenocysteine incorporation function. Mol. Cell. Biol. 26 , 4895-4910.

Peeters, R. P., Wouters, P. J., Kaptein, E., van Toor, H., Visser, T. J., and Van den Berghe, G. (2003). Reduced activation and increased inactivation of thyroid hormone in tissues of critically ill patients. J. Clin. Endocrinol. Metab. 88, 3202-3211.

Peeters, R. P., Wouters, P. J., van Toor, H., Kaptein, E., Visser, T. J., and Van den

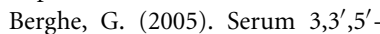
triiodothyronine (rT3) and 3,5,3'triiodothyronine/rT3 are prognostic markers in critically ill patients and are associated with postmortem tissue deiodinase activities. J. Clin. Endocrinol. Metab. 90 4559-4565.

Pingitore, A., Galli, E., Barison, A., Iervasi, A., Scarlattini, M., Nucci, D., L'Abbate, A., Mariotti, R., and Iervasi, G. (2008). Acute effects of triiodothyronine (T3) replacement therapy in patients with chronic heart failure and low-T3 syndrome: a randomized, placebo-controlled study. J. Clin. Endocrinol. Metab. 93, 1351-1358.

Plikat, K., Langgartner, J., Buettner, R., Bollheriner, L. C., Woenchhaus, U., Scholmerich, J., and Wrede, C. E. (2007). Frequency and outcome of patients with nonthyroidal illness syndrome in a medical intensive care unit. Metabolism 56, 239-244.

Redout, E. M., van der Toorn, A., Zuidwijk, M. J., van de Kolk, C. W. A., van Echteld, C. J. A., Musters, R. J. P., van Hardeveld, C., Paulus, W. J., and Simonides, W. S. (2010). Antioxidant treatment attenuates pulmonary arterial hypertension-induced heart failure. Am. J. Physiol. Heart Circ. Physiol. 298, H1038-H1047.

Rodriguez-Perez, A., Palos-Paz, F., Kaptein, E., Visser, T. J., DominguezGerpe, L., Alvarez-Escudero, J., and Lado-Abeal, J. (2008). Identification of molecular mechanisms related to nonthyroidal illness syndrome in skeletal muscle and adipose tissue from patients with septic shock. Clin. Endocrinol. (Oxf.) 68, 821-827.

Sano, M., Fukuda, K., Sato, T., Kawaguchi, H., Suematsu, M., Matsuda, S., Koyasu, S., Matsui, H., Yamauchi-Takihara, K., Harada, M.,
Saito, Y., and Ogawa, S. (2001). ERK and p38 MAPK, but not NF-kappaB, are critically involved in reactive oxygen species-mediated induction of IL- 6 by angiotensin II in cardiac fibroblasts. Circ. Res. 89, 661-669.

Schafer, F. Q., and Buettner, G. R. (2001). Redox environment of the cell as viewed through the redox state of the glutathione disulfide/glutathione couple. Free Radic. Biol. Med. 30, 1191-1212.

St. Germain, D. L. (1988). The effects and interactions of substrates, inhibitors, and the cellular thiol-disulfide balance on the regulation of type II iodothyronine 5'-deiodinase. Endocrinology 122, 1860-1868.

Sumita, S., Ujike, Y., Namiki, A., Watanabe, H., Kawamata, M., Watanabe, A., and Satoh, O. (1994). Suppression of the thyrotropin response to thyrotropin-releasing hormone and its association with severity of illness. Crit. Care Med. 22, 1603-1609.

Taniguchi, S., Kitamura, S., Kawachi, K., Doi, Y., and Aoyama, N. (1992). Effects of hormonal supplements on the maintenance of cardiac function in potential donor patients after cerebral death. Eur. J. Cardiothorac. Surg. 6, 96-101.

Torpy, D. J., Tsigos, C., Lotsikas, A. J., Defensor, R., Chrousos, G. P., and Papanicolaou, D. A. (1998). Acute and delayed effects of a single-dose injection of interleukin- 6 on thyroid function in healthy humans. Metabolism 47, 1289-1293.

Utiger, U. D. (1995). Altered thyroid function in nonthyroidal illness and surgery - to treat or not to treat? $N$. Engl. J. Med. 333, 1562-1563.

Valko, M., Leibfritz, D., Moncol, J., Cronin, M. T., Mazur, M., and Telser, J. (2007). Free radicals and antioxidants in normal physiological functions and human disease. Int. J. Biochem. Cell Biol. 39, 44-84.

Van der Berghe, G. (2002). Dynamic neuroendocrine responses to critical illness. Front. Neuroendocrinol. 23, 370-391.

Venditti, P., and Di Meo, S. (2006). Thyroid hormone-induced oxidative stress. Cell. Mol. Life Sci. 63, 414-434.

Wajner, S. M., Goemann, I. M., Bueno, A. L., Larsen, P. R., and Maia, A. L. (2011). IL-6 promotes nonthyroidal illness syndrome by blocking thyroxine activation while promoting thyroid hormone inactivation in human cells. J. Clin. Invest. 121, 1834-1845.

Williams, G. R., and Bassett, J. H. (2011). Deiodinases: the balance of 
thyroid hormone: local control of thyroid hormone action: role of type 2 deiodinase. J. Endocrinol. 209, 261-272.

Yu, J., and Koenig, R. J. (2000). Regulation of hepatocyte thyroxine $5^{\prime}$-deiodinase by $\mathrm{T} 3$ and nuclear receptor coactivators as a model of the sick euthyroid syndrome. J. Biol. Chem. 275, 38296-38301.
Zauberman, A., Zipori, D., Krupsky, M., and Ben-Levy, R. (1999). Stress activated protein kinase p38 is involved in IL-6 induced transcriptional activation of STAT3. Oncogene 18, 3886-3893.

Conflict of Interest Statement: The authors declare that the research was conducted in the absence of any commercial or financial relationships that could be construed as a potential conflict of interest.

Received: 29 September 2011; accepted: 10 January 2012; published online: 26 January 2012.

Citation: Wajner SM and Maia AL (2012) New insights toward the acute non-thyroidal illness syndrome. Front. Endocrin. 3:8. doi: 10.3389/fendo.2012.00008
This article was submitted to Frontiers in Thyroid Endocrinology, a specialty of Frontiers in Endocrinology.

Copyright (c) 2012 Wajner and Maia. This is an open-access article distributed under the terms of the Creative Commons Attribution Non Commercial License, which permits non-commercial use, distribution, and reproduction in other forums, provided the original authors and source are credited. 